\title{
Announcement of New Journal Sections
}

For the convenience of the reader, the Protein Journal will commence publication of specialized sections in various aspects of structure, function, design, genetics, enzymology, immunology, hormones, receptors, peptides, etc. In this issue, the journal starts with "The Neurotoxin Reports Section"

\section{The Neurotoxin Reports Section}

Authors are invited to submit research manuscripts on structure and activity of neurotoxins and neuro-active proteins and peptides and their targets of action.

This section will publish articles on structure and mechanisms of action of neurotoxins from bacteria, snake venoms, scorpions, fungi, marine organisms, spiders, wasps, bees, and other sources. These include molecular biology and other approaches to create mutants, chimeras and other structural designs with desired pre-selected, modified or modulated activities, as well as molecular immune response and innovative new vaccine designs with promising protective efficacies.

Neurotoxin Reports will also publish review articles on a current important aspect of structure, function and activity of neurotoxins or neuro-active proteins and peptides. Proposals for review articles should be presented for consideration by the Editorial Board prior to submitting a full manuscript.

\section{Disciplines}

Biochemistry, Molecular Biology, Molecular and cellular immunology, Neurology, Neurosciences, Neurophysiology, Protein structure and function, X-ray crystallography. 